\title{
APLICAÇÃO DO GERENCIAMENTO DE ROTINA DIÁRIO NO SETOR DE COMPRAS EM UMA EMPRESA DE IMPORTAÇÃO E EXPORTAÇÃO
}

\author{
APPLICATION OF DAILY ROUTINE MANAGEMENT IN THE PURCHASING SECTOR IN \\ AN IMPORT AND EXPORT COMPANY
}

\section{Luiz Felipe Oliveira de Assis ${ }^{1}, \&$ Marcos Wagner Jesus Servare Junior ${ }^{2 *}$}

${ }^{12}$ Centro Universitário Salesiano - UniSales, Av. Vitória, 950 - Forte São João, CEP 29017-950, Vitória - ES.

${ }^{1}$ felipeassistk@hotmail.com ${ }^{2}$ marcos.servare@ salesiano.br

\section{ARTIGO INFO.}

Recebido em: 06.07.2021

Aprovado em: 27.07.2021

Disponibilizado em: 17.08.2021

\section{Palavras-ChaVe:}

Processo; Compras; Matriz BASICO; GRD.

KEYWORDS:

Processes; Purchasing; BASICO Matrix; DRM.

*Autor Correspondente: Servare, M. W. J., Jr.

\section{RESUMO}

O presente artigo foi elaborado com o objetivo de demonstrar como o gerenciamento de rotina diário influencia na performance do departamento de compras. A partir do método de pesquisa-ação, aplicado em uma empresa de exportação e importação com sede no município de Vitória, Espírito Santo - Brasil, foi implementado uma série de correções nos processos já existentes e inclusos novos procedimentos na rotina operacional do setor utilizando ferramentas como a matriz BASICO, as quais impactaram diretamente e indiretamente nos outros departamentos da empresa que auxiliaram na execução das estratégias adotas. Foram descritos os principais gargalos que o setor tinha antes da implantação do GRD e os resultados após a aplicação da metodologia, resumidos em redução de custos, melhoria e confiabilidade dos processos e por fim, maior satisfação do cliente

\begin{abstract}
This paper was designed to demonstrate how daily routine management influences the performance of the purchasing department. From the actionresearch method, applied in an export and import company based in the city of Vitória, Espírito Santo Brazil, a series of corrections was implemented in the existing processes and new ones were included in the operational routine of the sector using tools such as BASICO matrix, which impacted directly and indirectly on the other departments of the company that helped in the execution of the adopted strategies. The main bottlenecks that the sector had before the implementation of the DRM and the results after the application of the methodology were added, summarized in cost reduction, improvement and reliability of processes and, finally, greater customer satisfaction.
\end{abstract}



empresa de importação e exportação. Brazilian Journal of Production Engineering, 7(3), 126-138.

\section{INTRODUÇÃO}

Diante do constante desenvolvimento social vivenciado nos tempos atuais, os consumidores, com acesso à cada vez mais informação através da tecnologia, têm aumentado seu nível de exigência dos serviços e produtos oferecidos pelas empresas. Neste contexto, as companhias têm buscado se reinventarem, tornando-se mais dinâmicas, flexíveis e ágeis em seus processos internos, oferecendo ao cliente não apenas o produto final ou serviço, mas a experiência em usá-los.

As atividades de importação e exportação estão entre principais operações econômicas de um país. Elas proporcionam escalabilidade na produção de bens e serviços, gerando crescimento e competitividade global, além da geração de emprego e renda. No Brasil, de acordo com dados da Secretaria de Comercio Exterior (SECEX, 2021), até a $3^{\circ}$ semana do mês de junho/2021, comparado a junho/2020, as exportações cresceram $69,9 \%$ e somaram U\$ $\$ 18,38$ bilhões. As importações cresceram $65,2 \%$ e totalizaram U\$ $\$ 11,23$ bilhões.

Segundo a Associação de Comércio Exterior do Brasil (AEB, 2020), para 2021, são projetados um total de U\$ $\$ 237,334$ bilhões em exportações, elevação de $13,7 \%$ em relação ao montante de U\$ 208,791 bilhões realizados em 2020, enquanto as importações estão previstas em U\$ $\$ 168,316$ bilhões, aumento de 7,3\% em relação aos U\$ 156,916 bilhões realizados em 2020. Estes números indicam um aparente crescimento no mercado em que a empresa atua.

A utilização de metodologias de gestão da qualidade, tem impacto tanto direta quanto indiretamente nos resultados operacionais e financeiros da companhia. A empresa em questão trata-se da Boa Praça Ship Supply, fundada em 1950, que possui sua matriz na cidade de Vitória - ES, além de duas filiais no estado do Rio de Janeiro, atuando na área de suprimentos em geral para embarcações de longo de curso e offshore.

A aplicação de um programa de qualidade, tem como requisito a participação e cooperação de toda a equipe funcional, assumindo cada um, a responsabilidade individual da qualidade das atividades desempenhadas com um propósito comum. Um dos principais fatores para que essa aplicação seja bem-sucedida é o envolvimento da alta gerência como uma facilitadora da implantação, atribuindo maior dinamismo à base funcional no exercício das atividades.

O Gerenciamento de Rotina Diário (GRD), por sua vez, é uma prática de monitoramento diário para conservar e aprimorar os padrões de qualidade, produtividade e controle dos processos, por responsabilidade dos colaboradores e procurando a eficiência organizacional através do acompanhamento das rotinas definidas (Campos e Falconi, 2004).

A técnica tem sido aplicada em larga escala no setor produtivo com diversas aplicações como em indústria de luminárias (Wendpap, de Almeida e da Silva; 2020), fábrica de cimentos (Silva, da Silva e Ferreira; 2020), de laticínios (Magalhães et al., 2020), de eventos infantis (Morais et al., 2020) e madeireiras (Grossi, Ananias e Peixoto, 2019), dentre outras. Para corroborar com o uso da técnica será utilizada a Matriz BASICO em conjunto, essa ferramenta proposta pelo governo análise a partir da combinação dos custos $\mathrm{x}$ benefícios $\mathrm{x}$ exequibilidade (Marinha do Brasil, 2008). 

empresa de importação e exportação. Brazilian Journal of Production Engineering, 7(3), 126-138.

O presente artigo tem por objetivo aplicar o GRD com a Matriz BASICO, de forma a verificar os gargalos, corrigir e controlar os processos de compra da Boa Praça Ship Supply. Este trabalho, ainda, se classifica como pesquisa-ação, conforme proposto por Thiollent (2011) para construir conhecimento visando a mudança do quadro observado, além de um dos autores deste trabalho atuar diretamente no setor em questão, acompanhando diretamente o impacto da implementação. No mais, a pesquisa é do tipo qualitativa, de natureza aplicada, visto que sua finalidade é gerar conhecimento para aplicações práticas na solução de problemas específicos, segundo (Gerhardt e Silveira, 2009).

A estrutura deste artigo é formada por quatro seções. A introdução desenvolvida nesta seção antecede o referencial teórico que é composto por duas subseções, onde a primeira subseção apresenta o conceito de gerenciamento da qualidade e a segunda, o gerenciamento da rotina diária. A terceira seção aborda o problema a ser resolvido neste artigo. A quarta seção referese ao plano de ação e metodologia utilizada para resolução do problema em questão.

\section{REFERENCIAL TEÓRICO}

\subsection{GERENCIAMENTO DA QUALIDADE}

A definição de gestão da qualidade é discutida há décadas e sofreu diversas mudanças ao longo do tempo. Conforme Carvalho e Paladini (2012) relatam, se for feita uma viagem no tempo e realizar a pergunta a um artesão do que significa qualidade e for comparado com trabalhadores de diversas épocas posteriores serão observadas respostas de sentido variado.

Os autores, ainda, destacam que artesão era um especialista que tinha domínio de todo o ciclo de produção, desde a concepção do produto até o pós-venda. Nessa época, o foco da qualidade era totalmente no produto, atendendo à necessidade do cliente. Por outro lado, conceitos como conformidade, metrologia e tolerância ainda engatinhavam.

A aquisição de materiais indiretos muitas vezes não possui altos valores negociados, mas a falta daquele material na indústria pode trazer muitos transtornos para a operação. Nesse caso, por exemplo, a qualidade fica aplicada à entrega do material na data combinada com o solicitante. Logo, o serviço ofertado de aquisição do material, muitas vezes é considerado um bom serviço quando os prazos são cumpridos conforme combinado entre as áreas e o fornecedor (Baily, 2000).

Com o passar dos anos, o conceito de gestão da qualidade foi evoluindo pressionado pela alta competitividade das empresas, que viram a necessidade de maximizar seus lucros através da aquisição e retenção de clientes, com o menor custo possível, diminuindo ao máximo índices de desperdícios, falhas, defeitos e retrabalhos.

A Figura 1 representa o histórico e evolução do conceito de controle da qualidade, antes tratado como uma ferramenta durante a execução do trabalho. Hoje, considerado como um dos pilares das empresas que buscam excelência em seus processos.

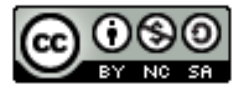



empresa de importação e exportação. Brazilian Journal of Production Engineering, 7(3), 126-138.

Figura 1. O movimento da qualidade no Brasil

\section{GESTÃO DA QUALIDADE}

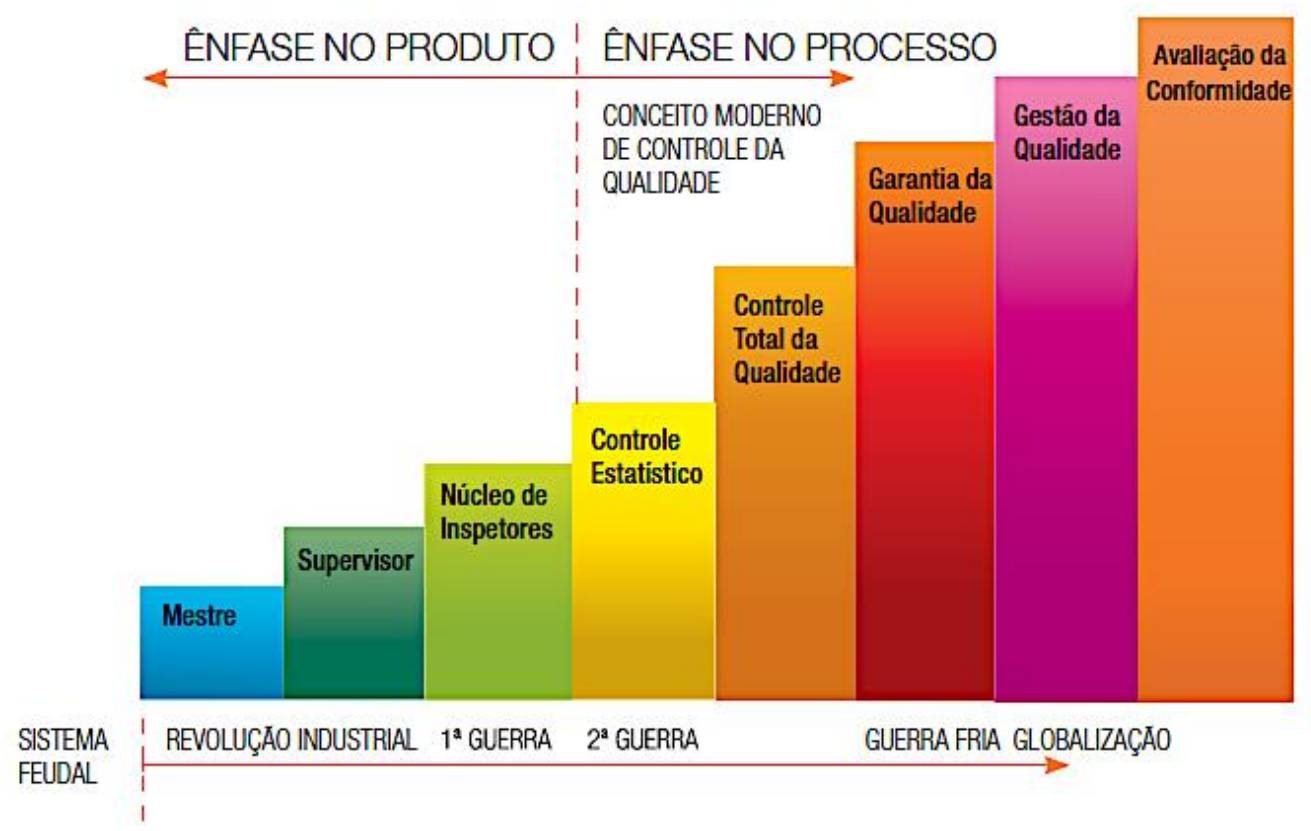

Fonte: Fernandes (2011)

Em Peinado e Graeml (2007), de acordo com Deming, a variabilidade do processo é a principal causa da não-qualidade. Sendo assim, seu princípio consiste na redução desta variabilidade, prevenindo defeitos, em vez de detectá-los, com forte aplicação do controle estatístico de processo. Deming ressalta também, que a qualidade era responsabilidade da alta gerência e a não-qualidade não acontecia simplesmente por culpa dos empregados.

\subsection{GERENCIAMENTO DA ROTINA DIÁRIA}

As empresas contêm uma série de tarefas e atividades que fazem parte de seus processos, que são executadas diariamente. Em paralelo, problemas e imprevistos surgem também frequentemente, muitas vezes causados pela falta de padronização e conformidade na execução desses processos.

De acordo com Carvalho e Paladini (2012), o gerenciamento da rotina é um processo que pode ser aplicado em qualquer departamento ou setor de uma organização que tenha como objetivo a plena satisfação do cliente por meio do controle sistemático e da melhoria contínua de cada microprocesso em base diária e progressiva.

Na Figura 2, tem-se um overview do processo de gerenciamento da rotina de forma macro, com suas respectivas correlações através do fluxo de processo. Como pode ser observado, toda a estrutura do gerenciamento da rotina parte do programa de gestão da qualidade no ambiente de trabalhado denominado 5S. 

empresa de importação e exportação. Brazilian Journal of Production Engineering, 7(3), 126-138.

Figura 2. Linhas básicas para a melhoria do gerenciamento da rotina

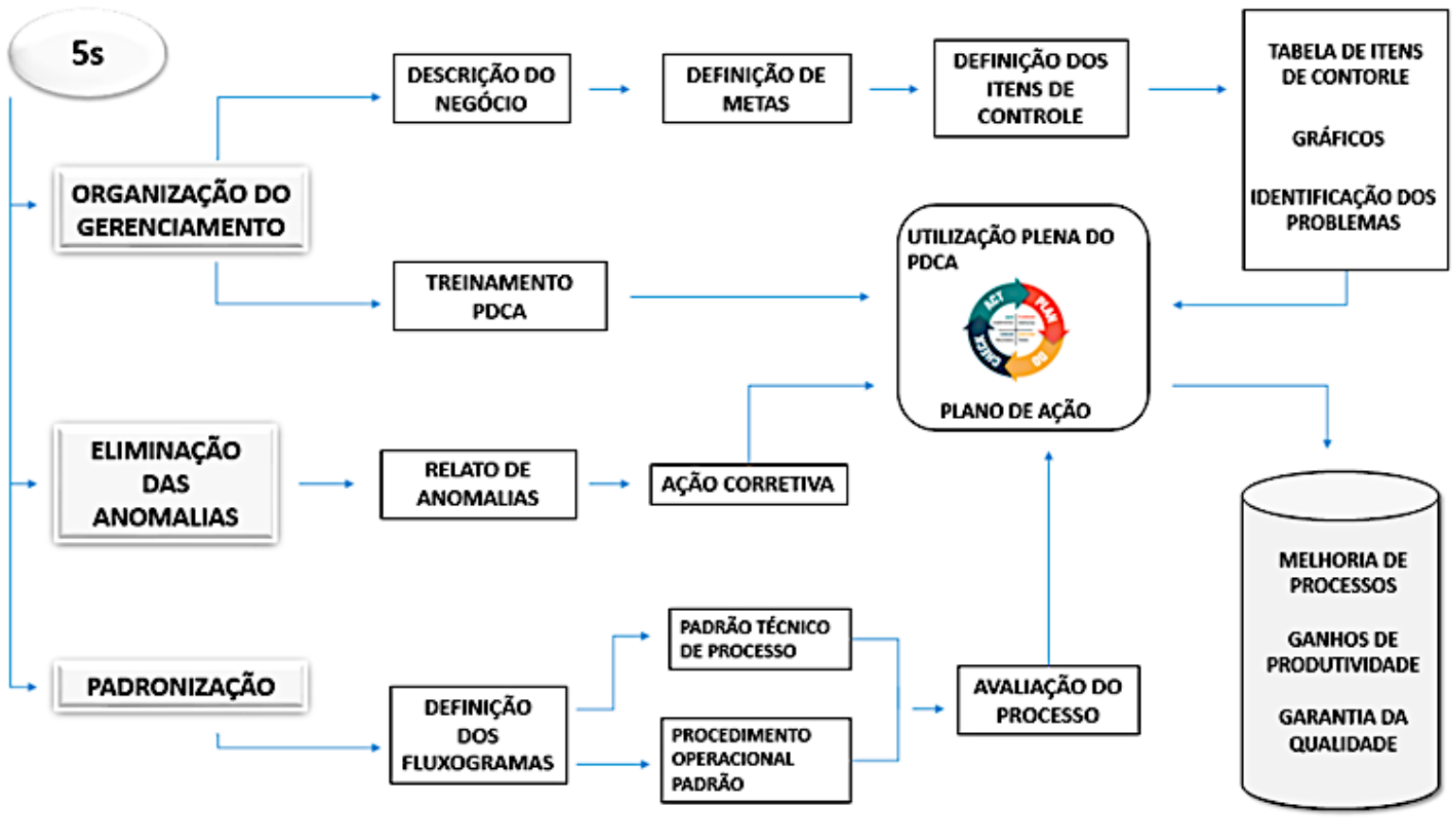

Fonte: Adaptado de Campos e Falconi (2004).

Segundo Campos e Falconi (2004), o gerenciamento da rotina é a base da administração e pode ser definido como ações e verificações diárias conduzidas para que cada pessoa possa assumir as reponsabilidades no cumprimento das obrigações conferidas a cada indivíduo e a cada organização.

Conforme evidenciado na Figura 2, para que o gerenciamento da rotina seja de fato eficiente, se faz necessário a utilização plena e constante do ciclo PCDA como plano de ação. Essa metodologia é uma maneira simples e eficaz de planejar, colocar em prática, controlar e agir sobre as falhas, para que se chegue à meta estabelecida e pode ser utilizada tanto para manutenção quanto para a melhoria das diretrizes de controle de um processo (Neves, 2007).

Para Carvalho e Paladini (2012), o gerenciamento da rotina é uma responsabilidade do chefe do departamento, mas o processo de melhoria deve se desenvolver com a participação e envolvimento de todo o pessoal, de modo permanente e contínuo.

\subsection{MATRIZ BASICO}

A matriz BASICO foi desenvolvida com base no balanço Custos $\mathrm{x}$ Benefícios $\mathrm{x}$ Exequibilidade e procura contemplar todos os tipos de "Clientes" das organizações. Para sua utilização, ainda segundo BRASIL (2015), deve-se atribuir para cada item a priorizar, uma nota que pode variar de 1 a 5 , de acordo com o sentimento negativo e positivo que expresse cada critério.

Os critérios analisados são: Benefícios para a organização, que representa o impacto da solução analisada nos resultados do processo; Abrangência, que retrata o montante da organização que será beneficiado com a melhoria do processo em questão; Satisfação do cliente interno, correspondente ao grau de satisfação gerado nos integrantes da organização que tem alguma relação com o processo; Investimentos requeridos, considerando o montante 

empresa de importação e exportação. Brazilian Journal of Production Engineering, 7(3), 126-138.

necessário para efetivação da melhoria do processo; Cliente externo satisfeito, que compreende o impacto que a melhoria do processo em questão terá sobre o cliente externo; Operacionalização, que se refere a aspectos como simplicidade da implantação, resistência à mudança e domínio da tecnologia necessária para aplicabilidade do processo. O Quadro 1 apresenta os parâmetros com as ferramentas de priorização para cada atributo da Matriz BASICO.

Quadro 1. Matriz BASICO

\begin{tabular}{|c|c|c|c|c|c|c|}
\hline Nota & B & $\mathbf{A}$ & $S$ & I & $\mathrm{C}$ & 0 \\
\hline 5 & $\begin{array}{c}\text { Benefícios de } \\
\text { vital } \\
\text { importância } \\
\text { para a } \\
\text { sobrevivência e } \\
\text { expansão dos } \\
\text { negócios da } \\
\text { instituição }\end{array}$ & $\begin{array}{c}\text { Total } \\
\text { abrangê } \\
\text { ncia (70 } \\
\text { a } 100 \% \\
\text { da } \\
\text { instituiç } \\
\text { ão) }\end{array}$ & $\begin{array}{l}\text { Muito grande, } \\
\text { servindo } \\
\text { como } \\
\text { excelente } \\
\text { referencial } \\
\text { dos } \\
\text { resultados na } \\
\text { qualidade. } \\
\end{array}$ & $\begin{array}{l}\text { Mínimo gasto em } \\
\text { recursos } \\
\text { disponíveis na } \\
\text { própria área ou } \\
\text { facilmente } \\
\text { conseguidos. }\end{array}$ & $\begin{array}{l}\text { Impacto positivo } \\
\text { muito grande na } \\
\text { imagem da } \\
\text { instituição no } \\
\text { relacionamento } \\
\text { com o mercado e } \\
\text { a comunidade. }\end{array}$ & $\begin{array}{l}\text { Grande facilidade } \\
\text { de implantação da } \\
\text { solução, com total } \\
\text { domínio da } \\
\text { "tecnologia } \\
\text { requerida". }\end{array}$ \\
\hline 4 & $\begin{array}{c}\text { Grandes } \\
\text { benefícios que } \\
\text { irão resultar em } \\
\text { significativos } \\
\text { lucros ou } \\
\text { avanços } \\
\text { tecnológicos. }\end{array}$ & $\begin{array}{l}\text { Abrangê } \\
\text { ncia } \\
\text { muito } \\
\text { grande } \\
\text { (de } 40 \text { a } \\
70 \% \text { da } \\
\text { instituiç } \\
\text { ão). }\end{array}$ & $\begin{array}{c}\text { Grande a } \\
\text { ponto de } \\
\text { gerar } \\
\text { demonstraçõe } \\
\text { s de } \\
\text { reconhecimen } \\
\text { to com as } \\
\text { atitudes } \\
\text { tomadas } \\
\end{array}$ & $\begin{array}{l}\text { Algum gasto de } \\
\text { recursos próprios } \\
\text { (dentro do } \\
\text { orçamento deste) }\end{array}$ & $\begin{array}{l}\text { Grandes reflexos } \\
\text { diretos nos } \\
\text { processos fim ou } \\
\text { nos outros } \\
\text { processos de } \\
\text { apoio que } \\
\text { atingem aos } \\
\text { clientes externos }\end{array}$ & $\begin{array}{c}\text { Boa facilidade } \\
\text { dependendo, } \\
\text { entretanto de } \\
\text { know-how / } \\
\text { tecnologia } \\
\text { externa, mas de } \\
\text { relativa } \\
\text { disponibilidade no } \\
\text { mercado. } \\
\end{array}$ \\
\hline 3 & $\begin{array}{l}\text { Benefícios de } \\
\text { razoável } \\
\text { impacto no } \\
\text { desempenho da } \\
\text { unidade } \\
\text { operacional. }\end{array}$ & $\begin{array}{l}\text { Abrangê } \\
\text { ncia } \\
\text { razoável } \\
\text { (de } 20 \mathrm{a} \\
40 \% \text { da } \\
\text { instituiç } \\
\text { ão). }\end{array}$ & $\begin{array}{l}\text { Médio, a } \\
\text { ponto de ser } \\
\text { facilmente } \\
\text { notada pelos } \\
\text { colegas de } \\
\text { trabalho. }\end{array}$ & $\begin{array}{l}\text { Gastos de recursos } \\
\text { além do } \\
\text { "orçamento" da } \\
\text { área, mas } \\
\text { aprovável em nível } \\
\text { imediatamente } \\
\text { superior. }\end{array}$ & $\begin{array}{l}\text { Bons reflexos } \\
\text { diretos nos } \\
\text { processos } \\
\text { finalísticos ou } \\
\text { nos processos de } \\
\text { apoio que } \\
\text { atingem } \\
\text { diretamente os } \\
\text { clientes externos }\end{array}$ & $\begin{array}{c}\text { Média facilidade } \\
\text { dependendo de } \\
\text { know-how de } \\
\text { difícil } \\
\text { disponibilidade no } \\
\text { mercado ou } \\
\text { mudanças } \\
\text { comportamentais/ } \\
\text { cultura } \\
\text { organizacional } \\
\end{array}$ \\
\hline 2 & $\begin{array}{l}\text { Algum } \\
\text { benefício no } \\
\text { desempenho } \\
\text { operacional } \\
\text { passível de ser } \\
\text { quantificado }\end{array}$ & $\begin{array}{l}\text { Abrangê } \\
\text { ncia } \\
\text { pequena } \\
(5 \mathrm{a} \\
20 \% \text { da } \\
\text { instituiç } \\
\text { ão) }\end{array}$ & $\begin{array}{l}\text { Razoável. } \\
\text { Existe, mas } \\
\text { não chega a } \\
\text { ser facilmente } \\
\text { notada pelos } \\
\text { colegas de } \\
\text { trabalho }\end{array}$ & $\begin{array}{l}\text { Gastos de recursos } \\
\text { que requerem } \\
\text { remanejamento de } \\
\text { verba/recursos do } \\
\text { orçamento da } \\
\text { instituição, a nível } \\
\text { de diretoria }\end{array}$ & $\begin{array}{l}\text { Pouco imp } \\
\text { nos proces } \\
\text { finalístic }\end{array}$ & $\begin{array}{c}\text { Pouca } \\
\text { exequibilidade, } \\
\text { dependendo de } \\
\text { ações ou decisões } \\
\text { políticas dentro da } \\
\text { instituição, ou } \\
\text { mudanças de } \\
\text { comportamentos/c } \\
\text { ultura } \\
\text { organizacional }\end{array}$ \\
\hline 1 & $\begin{array}{c}\text { Benefícios de } \\
\text { pouca expressão } \\
\text { quanto a } \\
\text { impactos } \\
\text { operacionais, } \\
\text { mas que irão } \\
\text { contribuir para a } \\
\text { disseminação da } \\
\text { qualidade na } \\
\text { instituição }\end{array}$ & $\begin{array}{l}\text { Abrangê } \\
\text { ncia } \\
\text { muito } \\
\text { pequena } \\
\text { (até 5\% } \\
\text { da } \\
\text { instituiç } \\
\text { ão) }\end{array}$ & $\begin{array}{l}\text { Pequeno, mas } \\
\text { o suficiente } \\
\text { para } \\
\text { contribuir } \\
\text { para a } \\
\text { disseminação } \\
\text { da Qualidade } \\
\text { Total, na } \\
\text { instituição }\end{array}$ & \begin{tabular}{|c|} 
Gasto de recursos \\
(\$, homens-hora, \\
equipamentos, etc.) \\
muito \\
significativos, \\
além do \\
previsto/orçado \\
requerendo decisão \\
político/estratégica \\
da instituição \\
\end{tabular} & $\begin{array}{l}\text { Nenhum reflexo } \\
\text { perceptível pelo } \\
\text { cliente externo }\end{array}$ & $\begin{array}{c}\text { Baixíssima } \\
\text { exequibilidade, } \\
\text { dependendo de } \\
\text { ações/ decisões } \\
\text { que extrapolam os } \\
\text { limites da } \\
\text { instituição. }\end{array}$ \\
\hline
\end{tabular}




\section{DEFINIÇÃO DO PROBLEMA}

Em relação a empresa objeto de estudo deste artigo, trata-se de uma companhia de comércio exterior, que trabalha principalmente com a exportação de suprimentos para embarcações de longo curso e offshore. Por estar inserida em um nicho de mercado com uma competitividade relativamente baixa, a empresa enxerga que tem a oportunidade de ser o principal player deste mercado no país, mas antes, é necessário arrumar a casa.

O setor a ser estudado é o departamento de compras. Para Ballou (2006), o departamento de compras contribui significativamente para o lucro de uma empresa representando de $40 \%$ a $80 \%$ do total gerado por receitas brutas. No modelo antigo em que a empresa atuava, a ênfase da área de compras estava em realizar tarefas rotineiras e processos operacionais, além do fato de que cada filial tinha sua equipe de compras atuando de modo independente, sob o critério de compras spot, e não conversavam entre si.

$\mathrm{O}$ setor de suprimentos, quando pensado de maneira estratégica e com processos amadurecidos, aumenta a produtividade operacional reduzindo custos e riscos de abastecimentos, propiciando vantagens competitivas juntos aos fornecedores, geração de valor e aumento do lucro líquido das empresas (Ballou, 2006). Em contrapartida ao objetivo de expansão, a companhia falha no quesito infraestrutura operacional, pois a sua Matriz não comporta espaço suficiente para produzir em sua capacidade máxima e, portanto, seu faturamento se mantém constante.

Além da falta de espaço para estocagem e movimentação de pallets, falta espaço para alocação de novos funcionários e ajuste no layout das salas para melhor distribuição dos funcionários no espaço. A falta de pessoas desencadeia uma série de problemas nos diversos setores da empresa. O acumulo de tarefas causa estresse nos colaboradores, fazendo com que o índice de turnover do RH da empresa fique alto, além de fazer com que os trabalhadores que optem por ficar, não rendam o máximo que poderiam.

Considerando as diversas alterações que vem sofrendo em seus processos, é percebido uma falta de comunicação, clareza e treinamento pessoal em relação às mudanças operacionais. Os colaboradores ficam sabendo das mudanças durante a execução de suas tarefas da forma antiga, causando retrabalho e perda de tempo.

\section{PLANO DE AÇÃO}

Após 4 meses de observação detalhada do funcionamento dos setores da empresa, entrevistas com colaboradores e coleta de dados extraídos do ERP Sankhya, foram apresentadas algumas ideias para melhoria de performance do departamento em reunião com a diretoria e gerência de compras. A partir da reunião de alinhamento com a diretoria e gerência da empresa, ficou definido a criação de uma central de compras na matriz.

\subsection{IMPLANTAÇÃO DO GRD NO DEPARTAMENTO DE COMPRAS}

Campos e Falconi (2004) propõem a execução do GRD em quatro macro fases, cada uma com um conjunto de ações necessárias para que os agentes de mudança sejam capazes absorver e implantar o gerenciamento da rotina diária na organização. Tais fases são demonstradas na Figura 3.

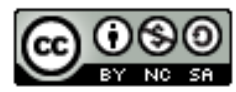


Citação (APA): Assis, L. F. O. de, \& Servare, M. W. J., Jr. (2021). Aplicação do gerenciamento de rotina diário no setor de compras em uma empresa de importação e exportação. Brazilian Journal of Production Engineering, 7(3), 126-138.

Figura 3. Fases do GRD

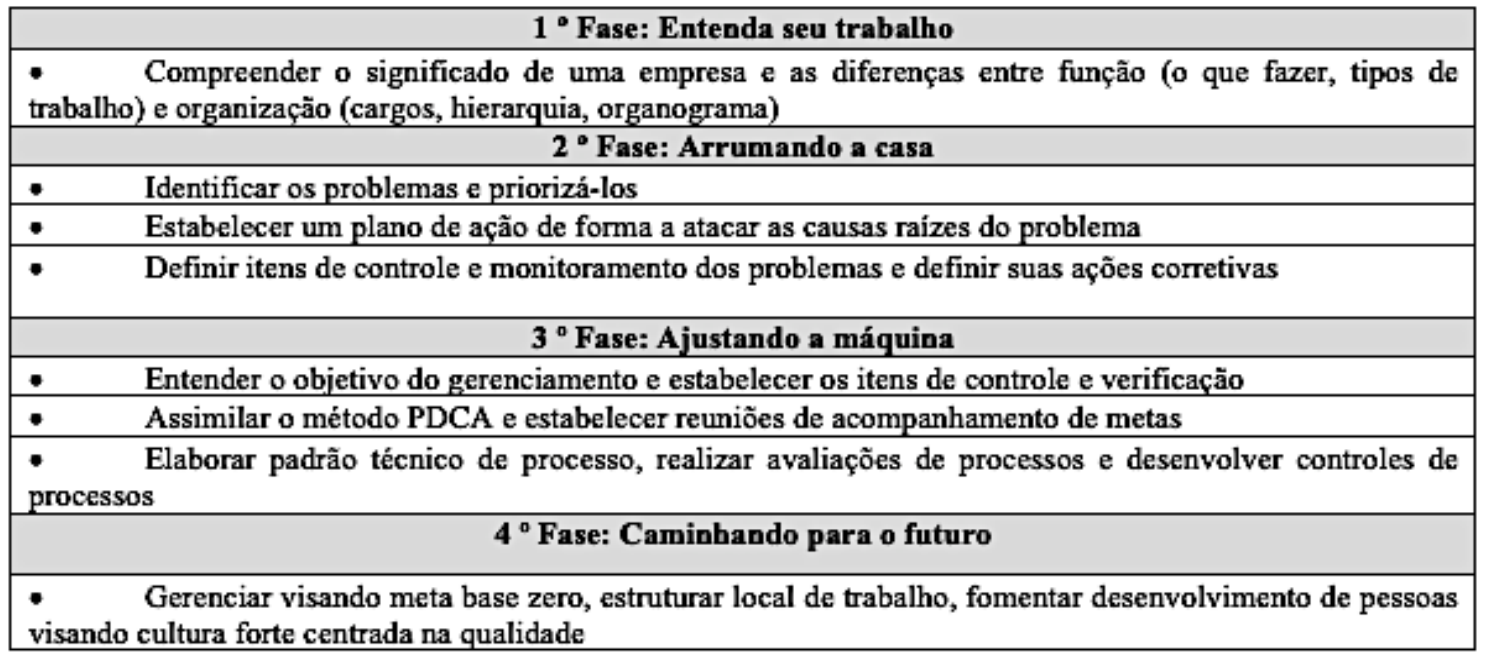

Fonte: Adaptado de Campos e Falconi (2004).

\subsection{FLUXO DE PROCESSOS}

A caracterização do processo de análise de giro dos produtos para ressuprimento do estoque, via fluxograma, é apresentado na Figura 4.

Figura 4. Fluxo de processos de compras

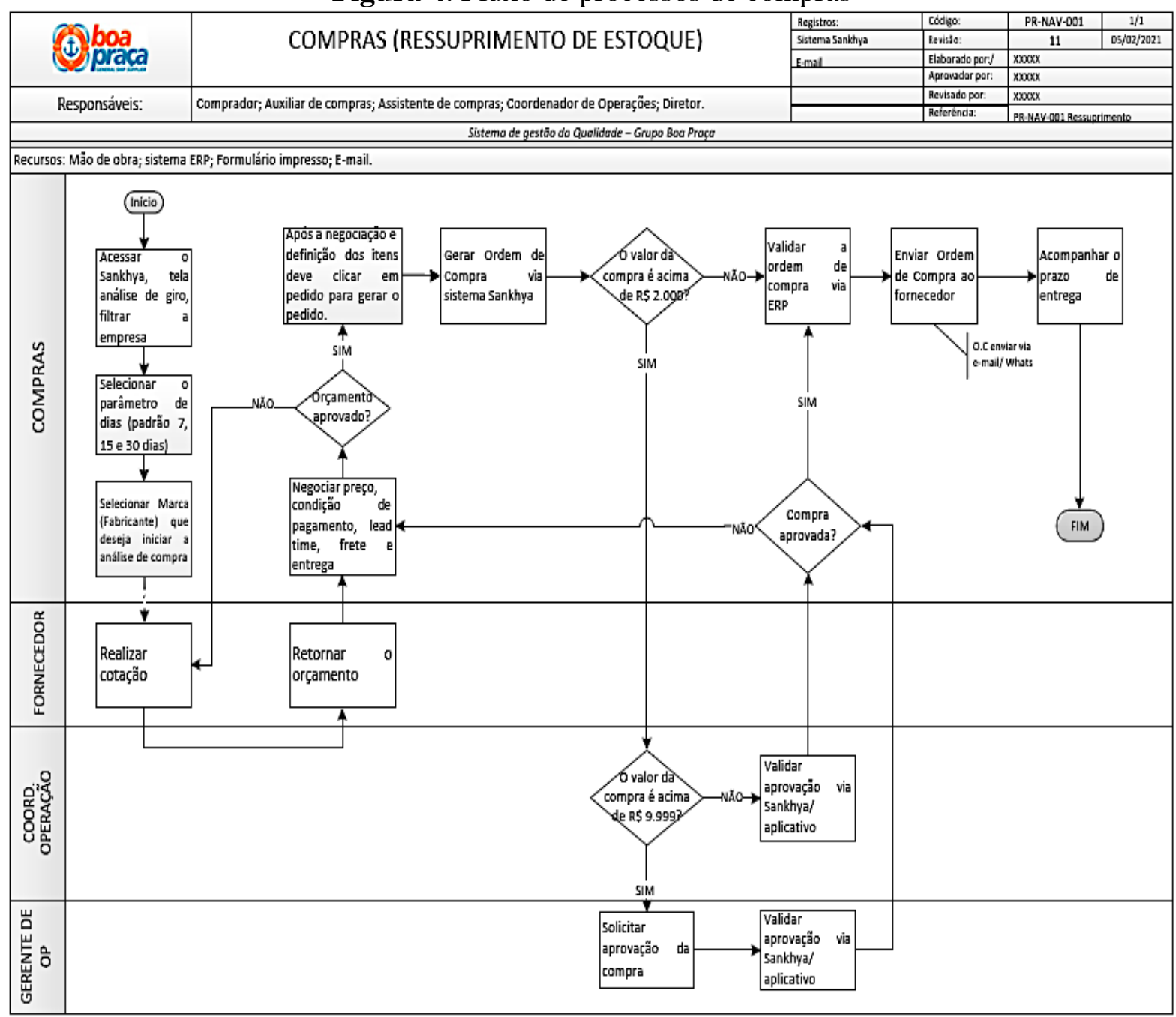



empresa de importação e exportação. Brazilian Journal of Production Engineering, 7(3), 126-138.

\subsection{PROCEDIMENTO OPERACIONAL PADRÃO (POP)}

Com a remodelagem dos processos da empresa, foi criado uma central de compras na Matriz, e o setor deixou de ser operacional e se tornou estratégico. Os compradores centrais passaram a atuar nos itens de curva A das bases, aumentando o poder de negociação da empresa movido pelo alto volume de compras, que são distribuídas para cada filial de acordo com sua demanda.

Com o objetivo de mitigar os possíveis erros durante as atividades diárias, foi criado um POP (Figura 5) elaborado para o setor de compras no processo de criação da ordem de compra, onde tem-se um índice de $40 \%$ de divergências entre ordens de compra e notas fiscais.

Figura 5. Procedimento Operacional Padrão

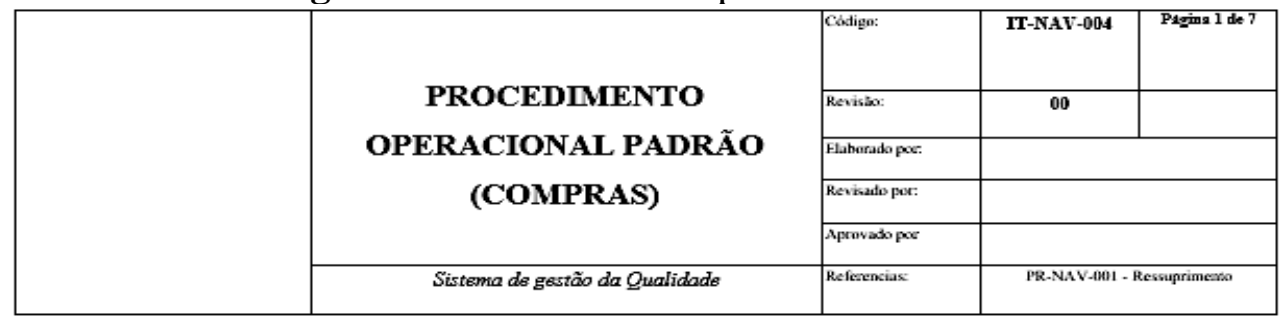

\section{ATIVIDADE CORRETIVA}

\section{NÃO CONFORMIDADE}

a) Não cumprimento do prazo;

b) Prorrogação de títulos;

c) Falta atualização de preços.

\section{ATIVIDADE CRITTCA}

a) Comprar produtos necessários;

b) Manter o lead-time no prazo;

c) Manter atualização de preço através de cotações.

\subsubsection{OBJETIVO DO SETOR DE COMPRAS}

- $\quad$ Analisar a curva de giro e manter o nível de estoque aceitável.

\subsubsection{DIRETRIZES DO PROCESSO}

- Cabe a função do comprador de processar os pedidos de compra, conforme gerenciamento de sua rotina diária;

- $\quad$ O comprador deve seguir sua carteira de fornecedores e a programação de compras estabelecida pelo gestor imediato;

- As negociações ou acordos contratuais deve ser direcionada ou validada pelo gestor imediato;

- Qualquer acordo verbal tratado entre o comprador e o fornecedor deve ser informado via e-mail ao gestor imediato para que possa validar a decisão;

- Se o comprador receber qualquer informação sobre ajustes na precificação deve formalizar via e-mail para gestor imediato e o gerente responsável;

- $\quad$ O recebimento só deve ser realizado mediante a apresentação da ordem de compra enviada pelo o Boa Praça na negociação;

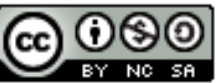



empresa de importação e exportação. Brazilian Journal of Production Engineering, 7(3), 126-138.

- $\quad$ gestor imediato é responsável por autorizar via sistema as compras acima de $\mathrm{R} \$$ de 2.000,00 até 9.999,00 reais, acima desse valor o Gerente de compras que deve aprovar;

- $\quad \mathrm{Na}$ falta do código do EAN, o Departamento de Compras deve contatar o fornecedor e solicitar o código, caso o fornecedor não tenha o código implantado deve negociar a possibilidade de implantação;

- As informações para a correção de cadastro devem ser encaminhadas para o Departamento de Compras com as informações adequadas, como as medidas das embalagens (largura, altura, profundidade), gramaturas peso liquido e bruto, caixa máster e a descrição completa do produto. Na falta de qualquer informação aqui citada o Departamento de compras não irá realizar o corrigir o cadastro.

\subsubsection{DEFINIÇÃO DOS ITENS DE CONTROLE}

- Tratar com o fornecedor as divergências de produtos, condições de pagamentos, valores acordados, transportadora, agendamento e a avaliação de entrega;

- Negociar a troca ou devolução dos produtos não conformes;

- Cadastrar os novos produtos com a descrição, gramatura, especificação das embalagens e o EAN;

- Atualizar as informações do fornecedor no cadastro de parceiros, principalmente contatos;

- Consultar no sistema Sankhya o relatório In-Full de corte para acompanhar os possíveis cortes que estão sendo gerados;

- Analisar trimestralmente os resultados das avaliações de entrega.

\subsection{MATRIZ BASICO}

Após a aplicação da matriz BASICO (Quadro 2) como forma de identificação e ordenação dos objetivos a serem priorizados, foi constatado que a definição de um mix de produtos na empresa hoje é a principal e mais urgente questão a ser tratada. Seus respectivos planos serão executados respeitando o fluxo de tarefas e investimentos correntes da empresa com prioridades máximas, a partir dos valores gerados pela matriz BASICO (Berriel, 2020).

Quadro 2. Matriz BASICO aplicada

\begin{tabular}{|c|c|c|c|c|c|c|c|}
\hline Possíveis Soluções & Benefícios & Abrangência & $\begin{array}{c}\text { Satisfação } \\
\text { Interna }\end{array}$ & Investimentos & Cliente & Operação & Resultado \\
\hline $\begin{array}{c}\text { Definição do mix de } \\
\text { produtos da empresa }\end{array}$ & 5 & 5 & 4 & 5 & 4 & 2 & 25 \\
\hline $\begin{array}{c}\text { Implantação do setor de } \\
\text { cadastro de produtos }\end{array}$ & 4 & 5 & 3 & 4 & 3 & 3 & 22 \\
\hline $\begin{array}{c}\text { Reuniôes semanais de } \\
\text { alinhamento entre o } \\
\text { time de compras e o } \\
\text { time de vendas }\end{array}$ & 3 & 3 & 1 & 5 & 3 & 4 & 19 \\
\hline $\begin{array}{c}\text { Reuniões semanais de } \\
\text { alinhamento entre o } \\
\text { time de compras e o } \\
\text { time de operações } \\
\text { logísticas }\end{array}$ & 3 & 3 & 1 & 5 & 3 & 4 & 19 \\
\hline $\begin{array}{c}\text { Implantação de check-in } \\
\text { e check-out via código } \\
\text { de barras nos processos } \\
\text { de entrada e saída de } \\
\text { mercadorias }\end{array}$ & 5 & 3 & 3 & 4 & 3 & 3 & 21 \\
\hline
\end{tabular}


Citação (APA): Assis, L. F. O. de, \& Servare, M. W. J., Jr. (2021). Aplicação do gerenciamento de rotina diário no setor de compras em uma empresa de importação e exportação. Brazilian Journal of Production Engineering, 7(3), 126-138.

\section{ANALISE DOS RESULTADOS}

A análise dos resultados ocorreu a partir de janeiro de 2021 - quando foi posto em prática o plano de ação para melhoria de performance do setor de compras - até a primeira quinzena de junho de 2021. No Gráfico 1, pode-se observar a queda no percentual de compras spot nas 3 filiais no intervalo em questão, tendo a matriz Vitória realizado um total de $\mathrm{R} \$ 662.184,25 \mathrm{em}$ compras, onde $\mathrm{R} \$ 7.966,49$ foram na modalidade spot, o que equivale a $1,2 \%$ - menor valor dos últimos 3 anos.

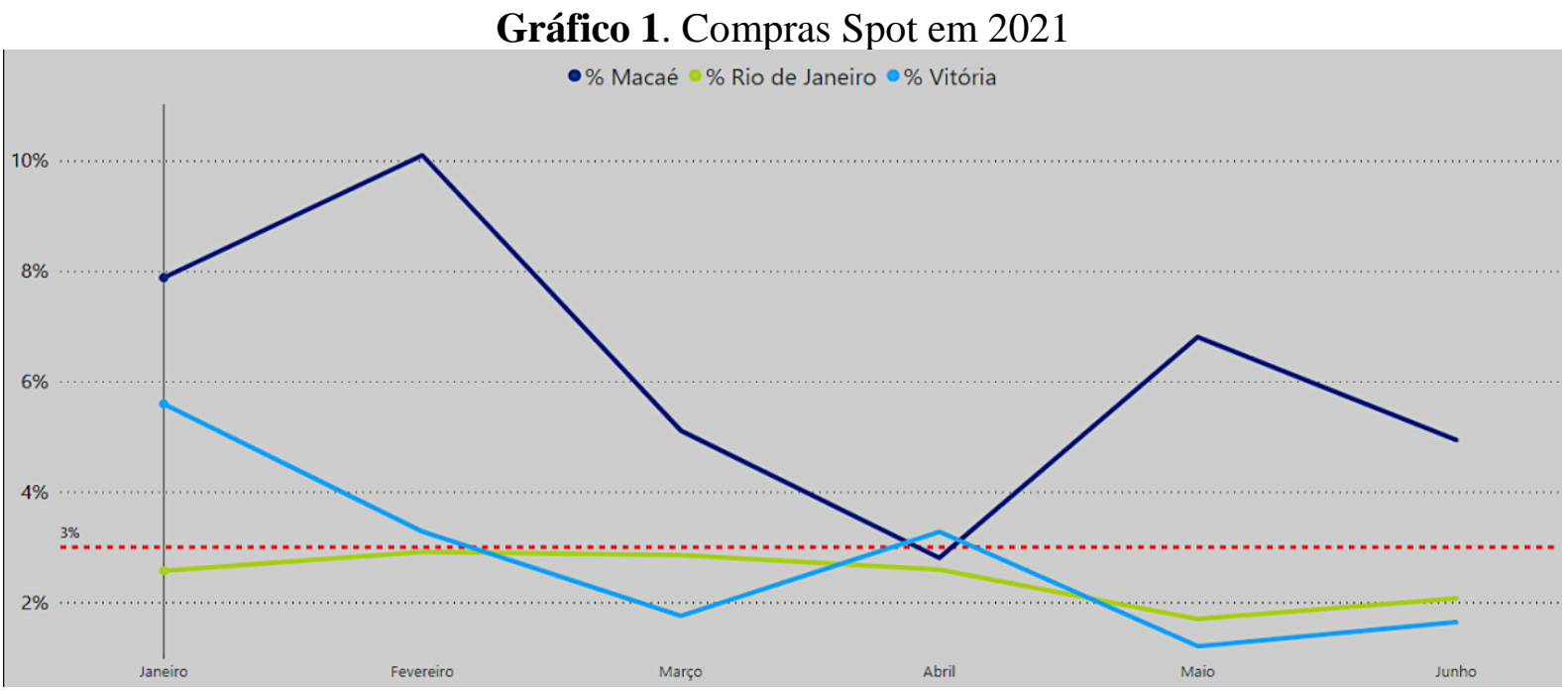

O Gráfico 2 evidencia a melhora nos resultados em comparação aos anos anteriores, em que o percentual médio de compra spot foi de 9,30\% em 2019, aumentando para 9,55\% em 2020 e caindo bruscamente para $3,25 \%$, se comparados os primeiros semestres.

Gráfico 2. Comparativo Compras Spot 2019 x 2020 x 2021

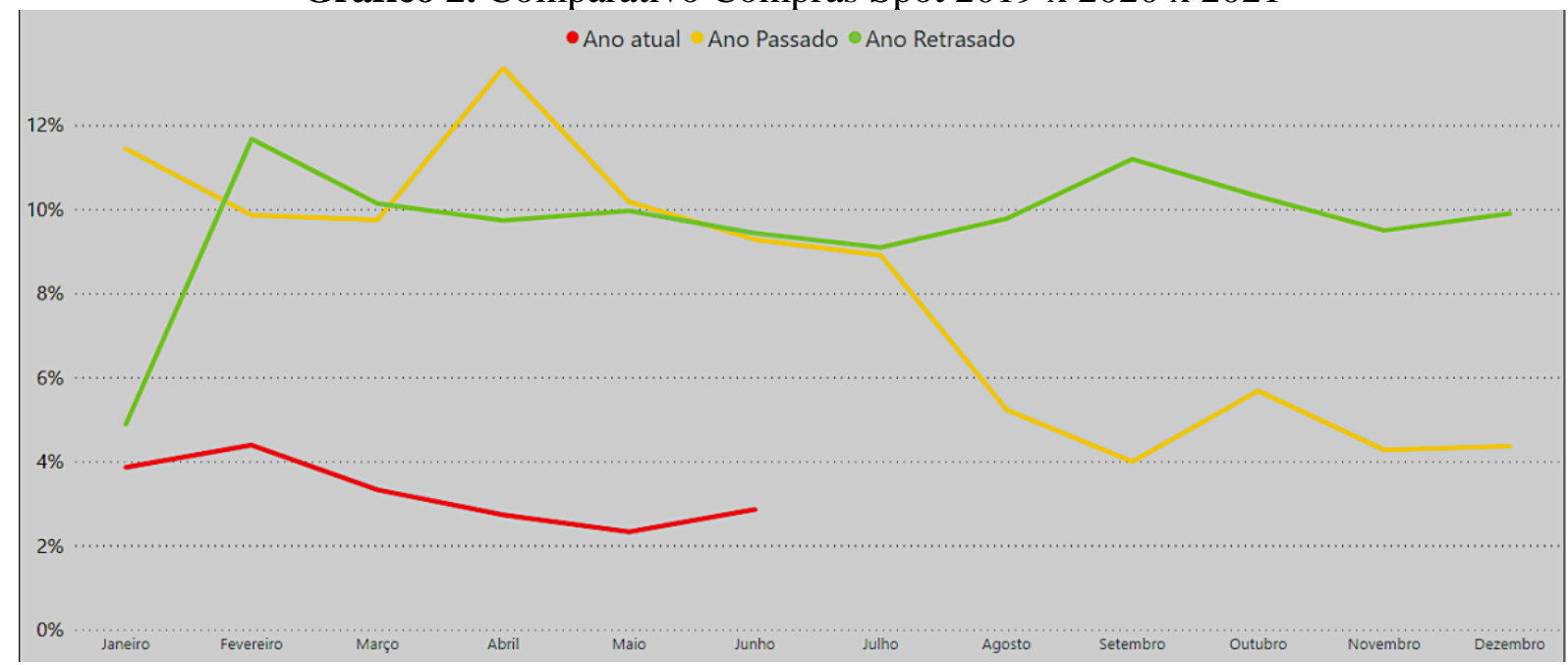

Em relação à ruptura de estoque demonstrada através do Gráfico 3, houve uma queda brusca principalmente na base de Macaé, onde 56,4\% do estoque se encontrava em ruptura no início do ano (uma queda de $37,1 \%$ se compararmos com os dias atuais). A filial de Macaé é a mais problemática para definição de mix de produtos por atender embarcações complexas com diversas peculiaridades. 

empresa de importação e exportação. Brazilian Journal of Production Engineering, 7(3), 126-138.

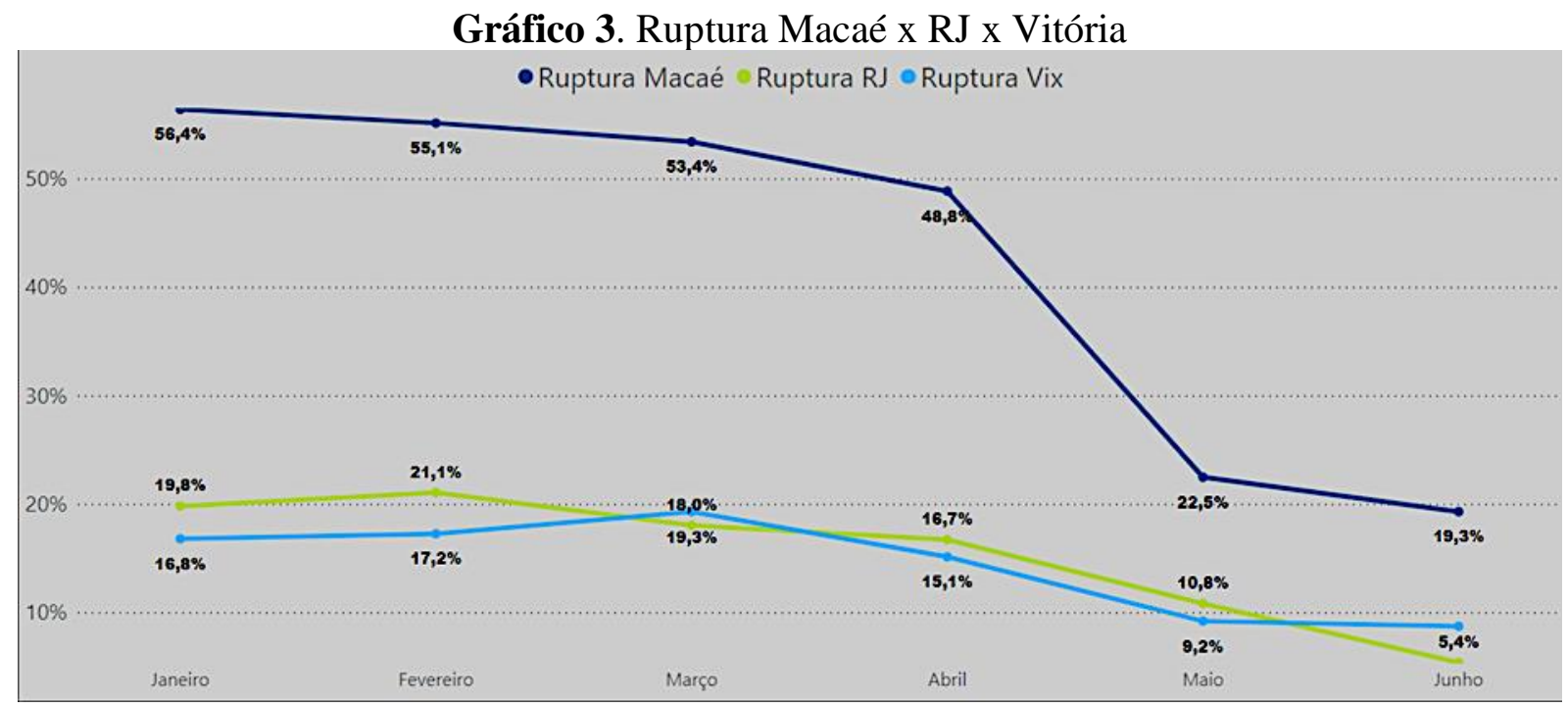

\section{CONSIDERAÇÕES FINAIS}

Levando em consideração os estudos apresentados neste trabalho, é percebido que a gestão da qualidade tem cada vez mais relevância nas organizações que buscam excelência em seus processos e foco no cliente. Vale ressaltar, que a proposta apresentada pelo estudo tem o intuito de introdução, em relação às necessidades da organização quando se fala em GRD, tornando as etapas apresentadas, ainda superficiais.

Conforme descrito no artigo em questão, o GRD é uma metodologia bastante eficiente no que tange ao aculturamento de uma organização em relação à sua gestão da qualidade, visto que é necessário que as pessoas desta organização alterem seus hábitos, mudem seu mindset para se tornarem agentes de mudança dentro da empresa. As ferramentas da qualidade e suas metodologias de nada valem sem as pessoas, que sempre serão o principal ativo de toda organização.

A implantação da central de compras na matriz, deu à organização um poder de compras justificado pela volumetria - que possibilitou negociações em um canal direto com as indústrias, com melhores preços, prazos de pagamentos e produtos com uma vida útil maior, visto que estes costumavam vir dos distribuidores já com um shelf life comprometido.

Ponderando-se os objetivos e soluções propostas ao longo do trabalho, foi possível acompanhar a implantação do gerenciamento de rotina no setor de compras de uma empresa de suprimentos para embarcações, como forma de padronização e melhoria de performance do departamento. Além disso, foram relatados os principais gargalos do setor e suas soluções. É aconselhável que a empresa continue executando as melhorias propostas de forma contínua até que a mudança de cultura que a organização pretende alcançar esteja tão forte que a gestão da qualidade ocorra de forma natural, por todos os seus colaboradores.

\section{REFERÊNCIAS}

AEB. (2021). Cenários, dados, particularidades, reflexos e projeções para o comércio exterior brasileiro em 2021. Recuperado de http://aeb.org.br/previsao-da-balanca-comercial$\underline{2021 /}$

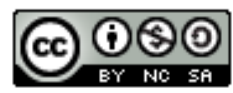


Citação (APA): Assis, L. F. O. de, \& Servare, M. W. J., Jr. (2021). Aplicação do gerenciamento de rotina diário no setor de compras em uma empresa de importação e exportação. Brazilian Journal of Production Engineering, 7(3), 126-138.

Baily, P., Farmer, D., Jessop, D., \& Jones, D. (2000). Compras: princípios e administração. São Paulo: Atlas, 8.

Ballou, R. H. (2009). Gerenciamento da Cadeia de Suprimentos-: Logística Empresarial. Bookman Editora.

Berriel, P. (2020). Proposta de priorização de esforços na gestão de uma Instituição de Ensino Superior por meio da metodologia da Estrela Decisória e da Matriz Básico. Unigranrio, Rio de Janeiro.

Brasil. Marinha do Brasil (2008). Secretaria Geral da Marinha. SGM-301: normas sobre administração financeira e contabilidade, 4, 5.

Brasil. Secretaria Geral da Marinha. (2011). Sgm-107. Normas Gerais de Administração. 4 Revisão, Vol. 1. Brasília.

Carvalho, M. M., \& Paladini, E. P. (2012). Gestão da Qualidade: Teoria e Caos. $2^{\mathrm{a}}$ Ed. Rio de Janeiro: Elsevier.

Campos, V. F. (2004). Gerenciamento da Rotina do Trabalho do Dia-Dia. $9^{\mathrm{a}}$ Ed. Nova Lima: INDG Tecnologia e Serviços Ltda.

Fernandes, W. A. (2011). O movimento da qualidade no Brasil.

Gerhardt, T. E., \& Silveira, D. T. (2009). Métodos de pesquisa. $1^{\text {a }}$ Ed. Porto Alegre: UFRGS.

Grossi, M. O., Ananias, L. F. N., \& Peixoto, M. G. M. (2019). Estudo de caso em uma empresa do setor madeireiro do alto paranaíba: proposta de implementação da gestão da qualidade total e da gestão da rotina. XXXIX Encontro Nacional de Engenharia de Produção, 13f. Santos.

Magalhães, C. S. et al. (2020). Controle da Qualidade Total, Gestão da Qualidade Total e Gestão da Rotina: Análise das Causas do Descarte de Queijo Ricota Produzido em um Laticínio Situado no Alto Paranaíba. XL Encontro Nacional de Engenharia de Produção, $13 f$. Foz do Iguaçu.

Morais, I.H.T. et al. (2020). Aplicação de ferramentas de gestão da qualidade em uma empresa de eventos infantis. XL Encontro Nacional de Engenharia de Produção, $16 f$. Foz do Iguaçu.

Peinado, J., \& Graeml, A. R. (2007). Administração da Produção: Operações Industriais e de Serviços. Curitiba: UnicenP.

Secex. (2021). Publicação Semanal. Balança Comercial Brasileira. $3^{\circ}$ Semana, junho de 2021. Recuperado de https://balanca.economia.gov.br/balanca/semanal/Nota.pdf

Silva, B. C., Da Silva, L. G., \& Ferreira, D. V. (2020). Gerenciamento de rotina no setor de ensacados de uma fábrica cimenteira no estado de Sergipe; . XL Encontro Nacional de Engenharia de Produção, 17f. Foz do Iguaçu.

Wendcap, M. V., Almeida, R. L. de, \& Silva, A. A. D. da. (2020). Implantação Do Gerenciamento Da Rotina Do Trabalho Do Dia A Dia Em Uma Indústria De Luminárias De Emergência: O Programa 5s. XL Encontro Nacional de Engenharia de Produção, 16f. Foz do Iguaçu.

Thiollent, M. (2011). Metodologia da Pesquisa-Ação. São Paulo: Cortez.

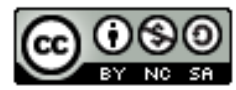

